\title{
Factors influencing creep resistance in discontinuously reinforced magnesium metal matrix composites
}

\author{
V. Sklenička ${ }^{1,2 *}$, K. Kuchařová ${ }^{1}$, M. Kvapilová ${ }^{1,2}$, M. Svoboda ${ }^{1,2}$ \\ ${ }^{1}$ Institute of Physics of Materials, Academy of Sciences of the Czech Republic, \\ Žižkova 22, CZ-616 62 Brno, Czech Republic \\ ${ }^{2}$ CEITEC-IPM, Institute of Physics of Materials, Academy of Sciences of the Czech Republic, \\ Žižkova 22, CZ-616 62 Brno, Czech Republic
}

Received 20 January 2015, received in revised form 9 March 2015, accepted 10 March 2015

\begin{abstract}
High-temperature strengthening mechanisms in various discontinuous magnesium metal matrix composites were examined by performing a close comparison between the creep behaviour of these composites and that of their selected magnesium matrix alloys, AZ91 and QE22. It was found that the magnesium AZ91 and QE22 alloys reinforced with 20 vol.\% alumina short fibres exhibit an improved creep resistance arising mainly from the load transfer effect and the existence of a threshold stress, respectively. The creep behaviour of 15 vol. $\%$ silicon carbide particle-reinforced magnesium AZ91 and QE22 alloys revealed that the creep resistance of the AZ91 alloy was increased through particle reinforcement; by contrast, the creep resistance of the powder reinforced QE22 alloy was deteriorated. A comparison between the creep characteristics of unreinforced squeeze-cast AZ91 and QE22 magnesium alloys and their hybrid composites reinforced with 8 vol.\% carbon short fibres and 15 vol.\% SiC particulates indicates the dominant importance of the choice of the composite matrix alloy and the reinforcement used.
\end{abstract}

K e y words: magnesium alloys, composites, creep properties testing, structure, fibres, interfaces

\section{Introduction}

The major current area of growth for the use of magnesium alloys is in the high volume commercial automotive sector, where there is an incentive for weight savings to maximize fuel economy and minimize emissions. To achieve an additional substantial increase in the use of magnesium in the automotive industry, it is necessary to utilize magnesium alloys in the engine and transmission components. These applications require a greater improvement in the hightemperature strength and creep resistance than is possible with the currently available commercial magnesium alloys.

The creep resistance of magnesium alloys is rather limited at temperatures above $400 \mathrm{~K}$. However, for engine components operating above $473 \mathrm{~K}$ new creep-resistant magnesium-based materials need to be developed. A marked improvement in the creep proper- ties of magnesium monolithic alloys can potentially be achieved through the production of composite materials, where the matrices consist of conventional magnesium alloys which are strengthened through the introduction of non-metallic fibres or particulates to form metal matrix composites (MMCs) [1, 2]. The present paper concentrates on this approach and examines the authors' own results and data from extensive creep experiments on two representative magnesium alloys (AZ91 and QE22) and their various discontinuously reinforced composites in order to compare directly their creep resistance and the relevance of the acting creep strengthening mechanisms.

\section{Experimental materials and procedures}

All of the experimental materials used in the study were fabricated at the Technical University of

*Corresponding author: e-mail address: sklen@ipm.cz 
Clausthal, Germany. Short-fibre reinforced and unreinforced blocks of the most common alloy AZ91 (Mg-9 wt.\%Al-1 wt.\%Zn-0.3 wt.\%Mn) and the high strength silver-containing alloy QE22 (Mg-2.5 wt.\% Ag2.0 wt.\% Nd rich rare earths- 0.6 wt. $\% \mathrm{Zr}$ ) were produced by squeeze casting [3-7]. The fibre preform consisted of planar randomly distributed $\delta$-alumina short fibres (Saffil $\mathrm{Al}_{2} \mathrm{O}_{3}$ fibres $\sim 3 \mu \mathrm{m}$ in diameter with varying lengths up to an estimated maximum of $\sim 150 \mu \mathrm{m})$. The final fibre fraction after squeeze casting in both composites was about $20 \mathrm{vol} . \%$. For convenience, the composites are henceforth designated AZ91 + Saffil and QE22 + Saffil. Unreinforced AZ91 and QE22 matrix alloys and their composites were subjected to a T6 heat treatment [5].

Powder metallurgy was used to fabricate $\mathrm{SiC}$ particle-reinforced and unreinforced AZ91 and QE22 alloys [8-10]. The particulate 15 vol.\%SiC-reinforced AZ91 and QE22 composites were prepared from gasatomized metal alloy powders of various sizes (ASTM sieve sizes 320 and 600 corresponding to mean particle diameters of 30 and $10 \mu \mathrm{m}$, respectively) and various shapes of the SiC particles (bulky particles-BL, rounded particles-HD). All materials were investigated in an as-received state after extrusion and after a T6 heat treatment, respectively.

The hybrid AZ91 and QE22 composites were produced by liquid infiltration of the fibre-particle preforms by matrix alloy melt via squeeze casting [11]. Details of the compositions and processing techniques of the hybrid composites will be given later.

The creep tests were carried out at temperatures from 423 to $523 \mathrm{~K}$ and at applied stresses from 10 to $200 \mathrm{MPa}$ in tensile creep-testing machines. The creep elongations were measured using a linear variable differential transducer and continuously recorded digitally and computer-processed.

Metallographic and fractographic investigations were conducted after creep testing using either a transmission electron microscope (TEM Philips CM12) with an operating voltage of $120 \mathrm{kV}$ or a scanning electron microscope (SEM Philips 505).

\section{Results and discussion}

\subsection{Monolithic and discontinuous fibre-reinforced squeeze-cast AZ91 and QE22 alloys}

The standard creep curves for the composite and the alloy may differ considerably. Selected creep curves are shown in Fig. 1 in the form of strain $\varepsilon$ versus time $t$ plots, for an absolute testing temperature, $T$, of $423 \mathrm{~K}$ and under comparable levels of the applied stress, $\sigma$. As demonstrated by the figure, significant differences were found in the creep behaviour of the composite
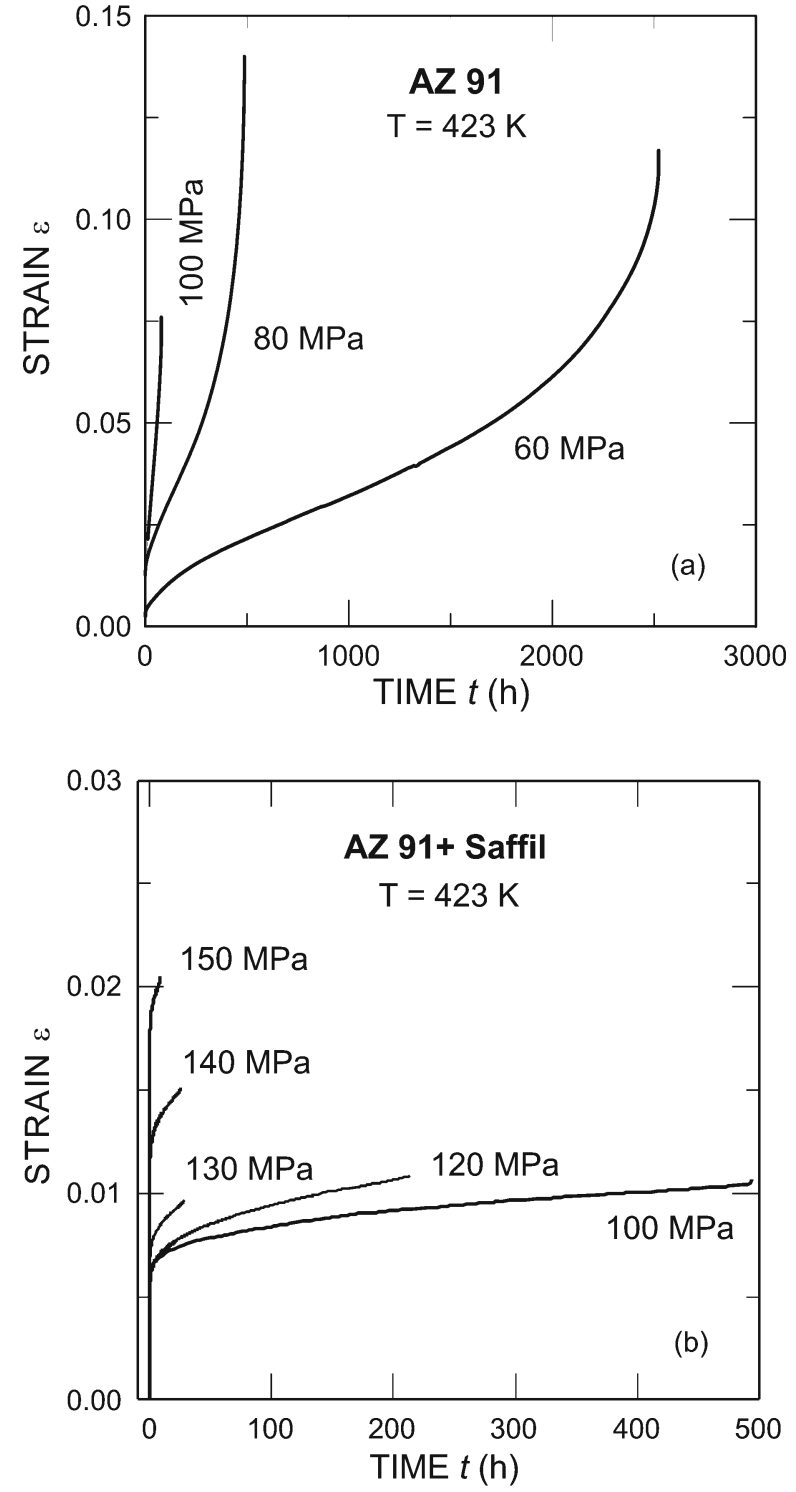

Fig. 1. Creep curves at $423 \mathrm{~K}$ for (a) the matrix alloy and (b) the AZ91 + Saffil composite.

when compared to its monolithic matrix alloy. First, the presence of the reinforcement leads to a substantial decrease in the creep plasticity, which is proved by the values of the total strains to fracture for the composite. Second, the composite exhibits markedly longer creep life than the alloy over the entire stress range used.

The creep data for the AZ91 and QE22 alloys and the AZ91 + Saffil and QE22 + Saffil composites at a testing temperature of $473 \mathrm{~K}$ are shown in Fig. 2, where the minimum creep rate $\dot{\varepsilon}_{\mathrm{m}}$ is plotted against the applied stress $\sigma$ on a logarithmic scale. Inspection of the creep data in Fig. 2 leads to two observations. First, the AZ91 + Saffil composite exhibits an improved creep resistance, typically by $>2$ orders of 


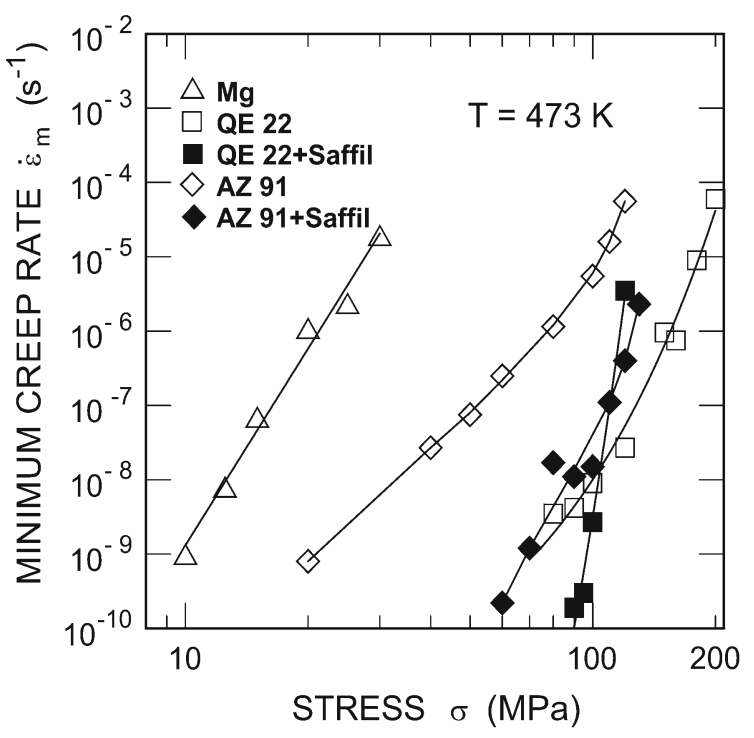

Fig. 2. Minimum creep rate versus stress for the monolithic alloys and their short fibre composites.

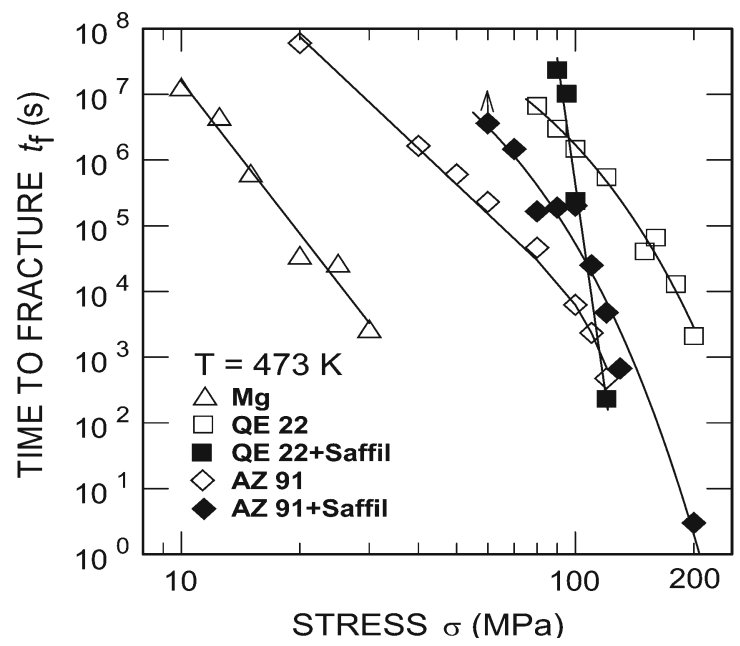

Fig. 3. Time to fracture versus stress for the same materials as in Fig. 2.

magnitude in comparison with the AZ91 monolithic alloy and, furthermore, the trends of these plots are different because the unreinforced alloy exhibits a decreasing value of the true stress exponent of creep rate $n=\left(\partial \ln \dot{\varepsilon}_{\min } / \partial \ln \sigma\right)_{\mathrm{T}}$ at the lower stresses, whereas the composite exhibits a higher value of $n$ with decreasing stress. Second, the creep resistance of the QE22 + Saffil composite is also considerably better than that of the matrix QE22 alloy but at the low stresses only ( $\leq 100 \mathrm{MPa})$. All magnesium alloys and their composites exhibit better creep resistance than commercially pure magnesium.

Figure 3 shows the variation of the time to fracture with the stress for the same specimens tested in
Fig. 2. The results for AZ91 alloy and its composite demonstrate that the creep life-times of the composite are up to one order of magnitude longer than for the monolithic alloy, although this difference decreases with increasing applied stress so that ultimately there is very little difference at stresses $>100 \mathrm{MPa}$. By contrast, the creep life of the QE22 + Saffil composite is markedly shorter than that of the unreinforced alloy at stresses $>100 \mathrm{MPa}$. The presence of reinforcement leads to a substantial decrease in the overall ductility of matrix alloy. Thus, the values of the strain to fracture $\varepsilon_{\mathrm{f}}$ in both composites were only $\sim 1-2 \%$. The strains to fracture in the monolithic alloys were markedly higher, typically up to $\sim 10-15 \%$ in the AZ91 alloy and up to $\sim 30 \%$ in the QE22 alloy [5].

Despite the general similarity of the creep behaviour of both composites, the presence of the same composition and amount of reinforcement in the unreinforced AZ91 and QE22 alloys results in a significantly different improvement of the creep resistance of the composite by comparison with the matrix alloy. Thus, it will only be appropriate here to analyse differences that can be inferred from a comparison between the creep characteristics of both composites and the unreinforced magnesium alloys.

The differences in creep behaviour of an AZ91 alloy and its AZ91 + Saffil composite are easily demonstrated by the plots shown in Fig. 2. The trend in these plots is different because the monolithic alloy exhibits a decreasing value in the stress exponent, $n$, at lower stresses and the composite exhibits a higher value of $n$ with decreasing stress. The increase in $n$ at the lower stresses in the composite is a fundamental property of many matrix composites and it is generally associated with the presence of a threshold stress marking a lower limiting stress below which no measurable creep rate can be achieved [6]. The data for the unreinforced alloy suggest a transition to a value of $n$ close to $\sim 3$ at lower stress. A value of $n=3$ suggests that viscous glide is the rate-controlling mechanism in the matrix alloy and the increase $n$ at the higher stresses is then due to the detachment of the dislocations from their solute atmospheres. Since the creep data in Fig. 2 suggest the presence of a threshold stress in the composite, it is possible to extend the analysis by determining the magnitudes of the threshold stresses at 423 and $473 \mathrm{~K}$. Threshold stress may be estimated by extrapolating extensive sets of creep data to strain rates where the plots lie vertical [12], but in practice the data for the composite in Fig. 2 are too limited to use this procedure and it is therefore necessary to plot, on linear axes, the datum points for the strain rates raised to a power of $1 / n$ against the values of the applied stress and then to extrapolate to give the threshold stresses at zero strain rate [13]. Taking a value of $n=3$ for viscous glide [6], Fig. 4 shows this plot for the composite for the two testing temperatures and the extrapola- 


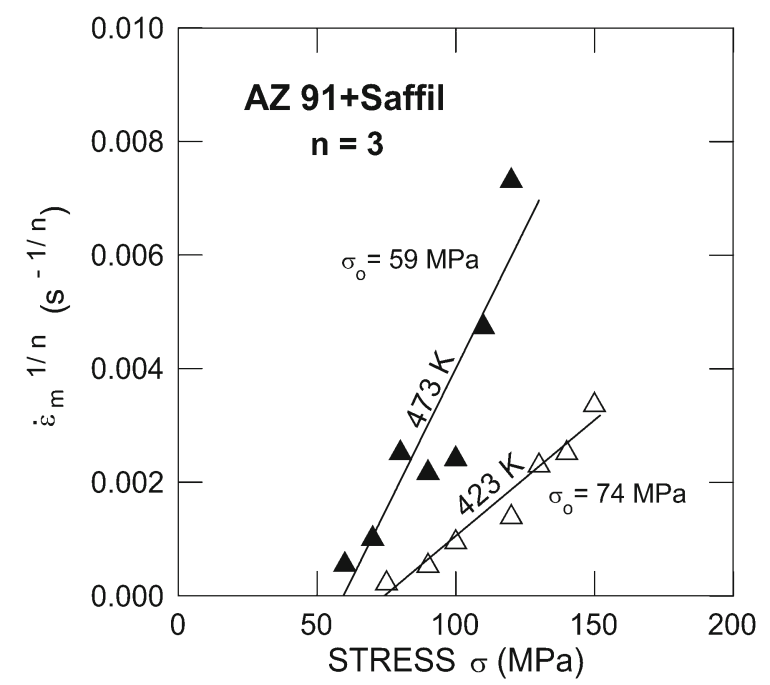

Fig. 4. Procedure for determining the threshold stress in the AZ91 + Saffil composite at 423 and $473 \mathrm{~K}$ using a stress exponent of $n=3$.

tions give threshold stresses of $\sim 74$ and $\sim 59 \mathrm{MPa}$ for 423 and $473 \mathrm{~K}$, respectively, which indicates a temperature dependence of the threshold stress.

As already shown, the presence of short fibre reinforcement leads to a reduced creep rate in the AZ91 + Saffil composite by two or three orders of magnitude (Fig. 2). Such a difference can arise when significant load transfer partitions the external load between the matrix and the reinforcement [14]. In the presence of load transfer, the creep data may be successfully reconciled by putting the ratios of the minimum creep rates of the composite and the rates of the matrix alloy at the same loading conditions, equal to a factor given by $(1-\alpha)^{n}$, where $\alpha$ is a load transfer coefficient having values lying within the range from 0 (no load transfer) to 1 (full-load transfer). Thus, the values of $\alpha$ inferred from the data in Fig. 2 using $n=3$ are within the range of 0.8 to 0.9 . The predicted values are in reasonable agreement with the theoretical predictions according to an analytical treatment by Nardone and Prewo [15]. Further, greater creep resistance exhibited by the AZ91 + Saffil composite may arise from a substructural strengthening effect due to the increased dislocation density which is present in the composite because of the thermal mismatch between the matrix and fibres.

The stress dependence of the minimum creep rate for the QE22 + Saffil composite and its unreinforced alloy in Fig. 2 shows that the creep behaviour of the composite is similar to that of the alloy in regard to the high stress exponents $n$, which suggests that the creep behaviour of both materials may be controlled by precipitation strengthening due to the interaction of the fine precipitates with mobile dislocations. While the values of the apparent stress exponent for the al-
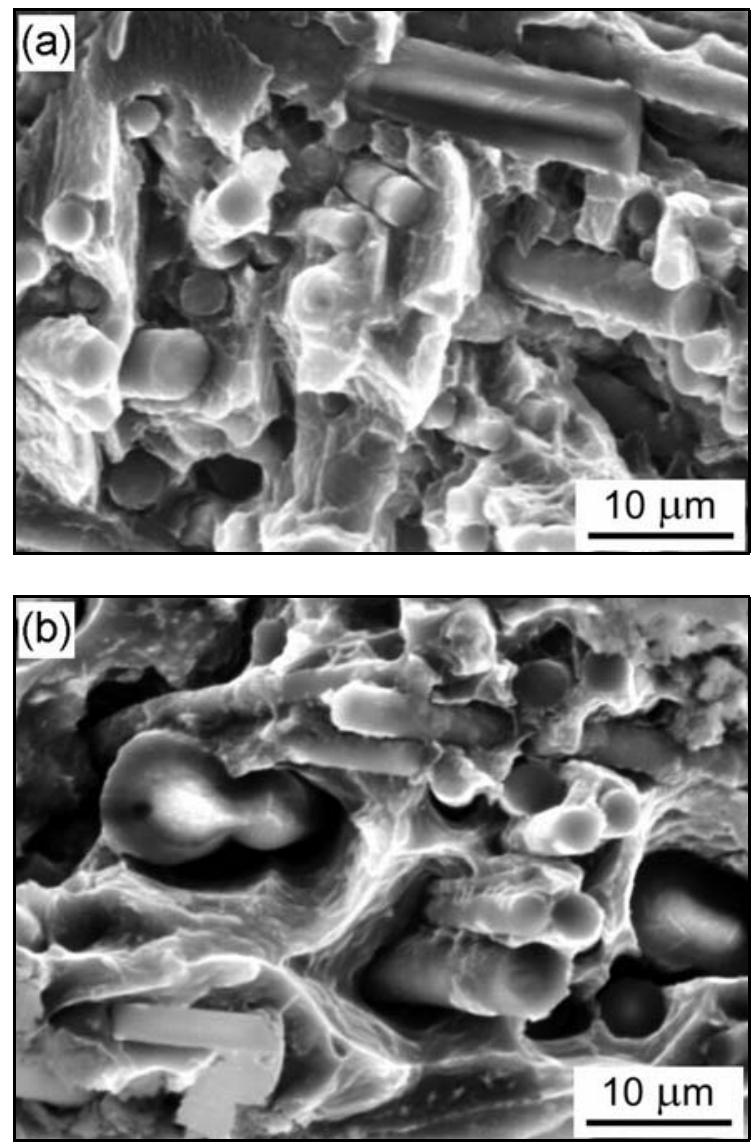

Fig. 5. SEM micrographs showing the creep fracture surfaces after testing at $473 \mathrm{~K}$ : (a) the AZ91 + Saffil composite (stress $70 \mathrm{MPa}$ ), (b) the QE22 + Saffil composite (stress $120 \mathrm{MPa}$ ).

loy slightly decrease with decreasing applied stress, no curvature on the plot of the creep rate versus stress for the QE22 + Saffil composite was found. The experimental data describe the creep behaviour of the composite only over three orders of magnitude of creep rate or less. Thus it is difficult to establish whether the stress exponent is genuinely constant, or increases with decreasing the applied stress, indicating the potentiality of the threshold stress. However, it is nearly impossible for technical reasons to perform additional creep tests at very low stresses. Further, no values of a load transfer coefficient $\alpha$ for the composite have been obtained due to insufficient creep data and thus no valuable information regarding the value of the true stress exponent $n$. It can be concluded that the QE22 + Saffil composite exhibits better creep resistance than its monolithic alloy at low stresses only. This difference decreases with increasing stress and there is a tendency for the reinforcement to have a detrimental effect on the creep strength at the highest stresses.

The creep behaviour of the composites may be substantially influenced by the matrix/fibre interfaces 
[16]. Weak matrix/reinforcement bonding may lead to inferior creep properties of the composite. Thorough fractographic investigations of the AZ91 + Saffil composite did not reveal either substantial creep fibre cracking and breaking or any substantial debonding at the interfaces between the fibres and the matrix due to creep (Fig. 5a). This result is supported by the response observed through acoustic emission monitored during the creep testing of the AZ91 + Saffil composite [17]. By contrast, an intensive debonding was revealed at the creep fractures at the QE22 + Saffil composite (Fig. 5b). Thus, in the limit of zero interface strength, where no stress can be transmitted to the fibres, the composite may be weaker than the matrix alone. Further, detailed microstructure investigation [5] revealed enhanced precipitation of secondary phases at the interfaces in the QE22 + Saffil composite, which can detrimentally affect the creep behaviour of the composite by progressive interfacial debonding and matrix depletion, producing precipitate inhomogeneity and deficiency in the matrix precipitate structure and leading to the composite weakening. As a consequence of these features, the Saffil reinforcement in the QE22 alloy gives a more modest improvement in the creep properties than it does in the AZ91 alloy.

\subsection{Particle-reinforced composites fabricated by powder metallurgy}

Particle- and/or particulate-reinforced MMCs may give more modest improvements in the creep properties than their fibre-reinforced counterparts; nevertheless, they can be formed into useful shapes using conventional metal working processes such as powder metallurgy methods and extrusion, and they also exhibit more isotropic properties $[18,19]$. As already mentioned in Section 2, powder metallurgy was used in this work to fabricate the AZ91 and QE22 matrix alloys and their $\mathrm{SiC}$ particle-reinforced composites.

The stress dependences of the minimum creep rates at $473 \mathrm{~K}$ for the AZ91 monolithic alloy and the AZ91 +15 vol.\% SiC composite (Fig. 6a) and the stress dependences of the minimum creep rates for the QE22 monolithic alloy and the QE22 + 15 vol.\% SiC composite (Fig. 6b) show that the reinforcing effect of $\mathrm{SiC}$ particles on the creep resistance is not uniform and depends strongly on the matrix alloy. While the creep resistance of the AZ91 alloy is improved through particle reinforcement, the creep resistance of the reinforced QE22 alloy is markedly lower than that of monolithic QE22 alloy and the particle size influences the creep behaviour significantly. These results confirm earlier results published by Moll et al. [20].

The microstructure of the QE22 alloy after T6 heat treatment is very complex and has been extensively studied by Svoboda et al. [8]. The matrix of the $\mathrm{QE} 22+15$ vol.\% $\mathrm{SiC}$ composites after a $\mathrm{T} 6$ heat treat-
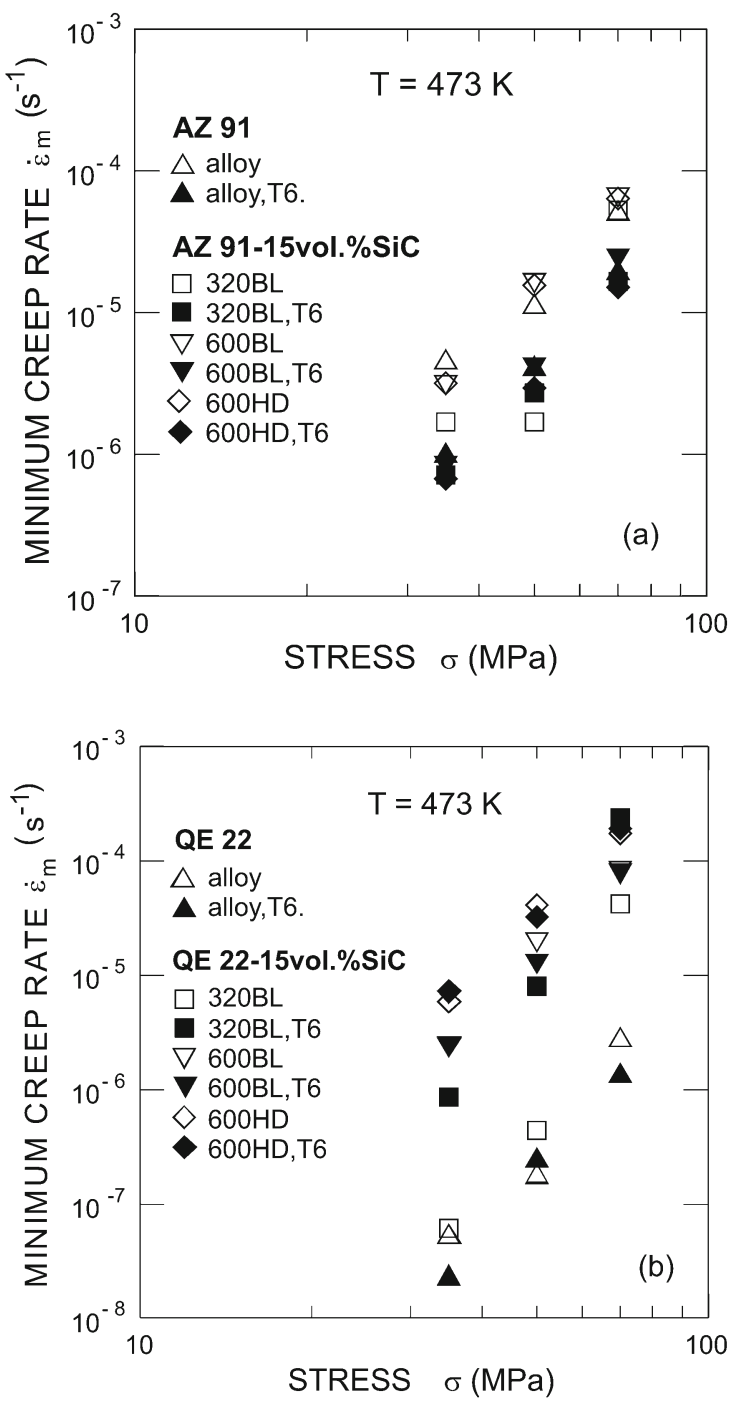

Fig. 6. Stress dependences of the minimum creep rates at $473 \mathrm{~K}$ for (a) the AZ91 monolithic alloy and the AZ91 + 15 vol.\% SiC composites and (b) the QE22 alloy and the $\mathrm{QE} 22+15$ vol.\% SiC composites, in as-received state and after T6 heat treatment.

ment contained all the phases revealed in the QE22 monolithic alloy except only that the coherent GP zones were missing. A pronounced precipitation of an Nd-rich phase occurred at the $\mathrm{SiC} /$ matrix interfaces (Fig. 7). Thus, it is evident that the $\mathrm{SiC} /$ matrix interface acts as a nucleation site for this phase.

The enhanced precipitation of Nd-rich phases at the $\mathrm{SiC} /$ matrix interface in the $\mathrm{QE} 22+15 \mathrm{vol} . \% \mathrm{SiC}$ composite after $\mathrm{T} 6$ heat treatment and during creep can affect detrimentally the creep behaviour in two possible ways. First, matrix depletion due to interfacial precipitation in the composite can produce precipitate inhomogeneity and deficiency in the matrix precipitate structure, leading to the composite weakening. Second, Moll et al. [20] and Sklenička et al. [10] 


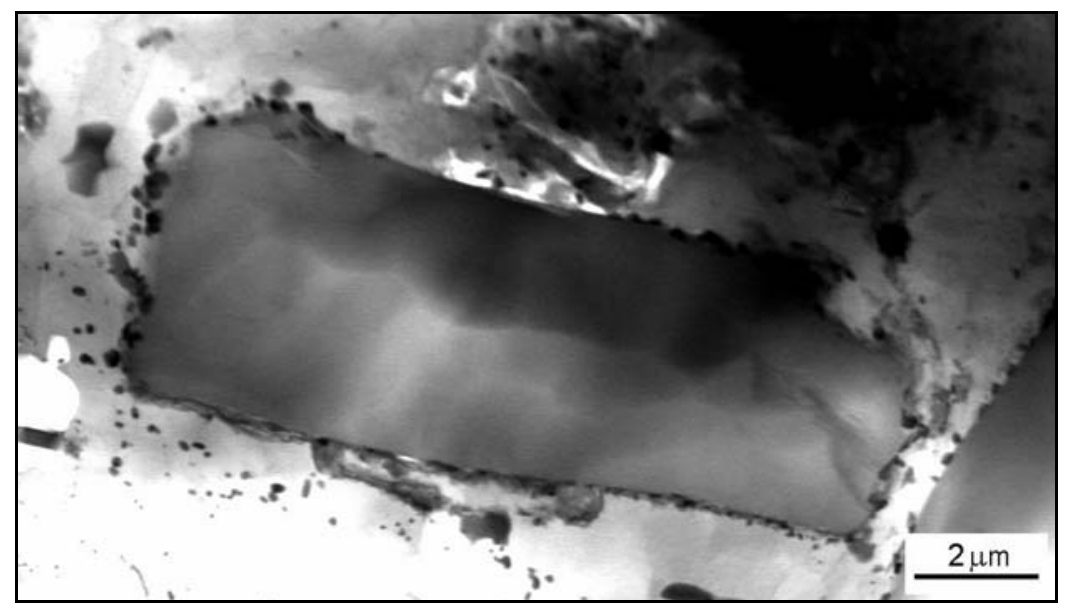

Fig. 7. STEM micrographs showing pronounced precipitation of an Nd-rich phase at the SiC/matrix interfaces in QE22 +15 vol.\% SiC composite after T6 heat treatment and creep test at $35 \mathrm{MPa}$ and $473 \mathrm{~K}$.

have proposed that the poor creep resistance of the $\mathrm{QE} 22+15$ vol.\% SiC composite may be explained by taking into account interfacial sliding as an additional creep mechanism acting in the composite. As a consequence of interfacial sliding, many cavities can occur at interfaces, giving rise to the formation of microscopic cracks and the debonding of matrix/SiC interfaces. It is generally accepted that intergranular creep cavities are nucleated at the particles due to high local stress concentration caused by grain boundary sliding (Sklenička [21]). In a similar way, the necessary stress conditions can be developed on interfacial particles due to the interaction of interfacial sliding and interfacial precipitates. In conclusion, an intensive debonding of matrix/ $\mathrm{SiC}$ interfaces may explain the inferior creep resistance of the $\mathrm{QE} 22+15$ vol.\% $\mathrm{SiC}$ composite.

\subsection{Hybrid composites}

Short-fibre reinforced magnesium MMCs are expensive and have anisotropic properties. The partial replacement of expensive short fibres by cheap particulates reduces the cost as well as anisotropy [18, 19, 22, 23]. Thus, hybrid composites seem to be the best choice. To demonstrate the effect of the hybrid reinforcements on the creep properties, an informative creep study on hybrid magnesium composites was performed. Again, the magnesium AZ91 and QE22 alloys were selected as the matrix alloys of these hybrid composites. Hybrid composites were produced in such a way that the fibre-particle preform consists of 8 vol. $\%$ carbon short fibres and 16 vol.\% blocky-shaped $\mathrm{SiC}$ 600 BL particles [11]. Both monolithic AZ91 and QE22 alloys and their composites were prepared by squeeze casting and investigated in their as-cast states.

The creep tests were carried out at a temperature of $473 \mathrm{~K}$ and at the applied stresses 35,50 and $70 \mathrm{MPa}$ during a creep exposure, respectively. The creep data
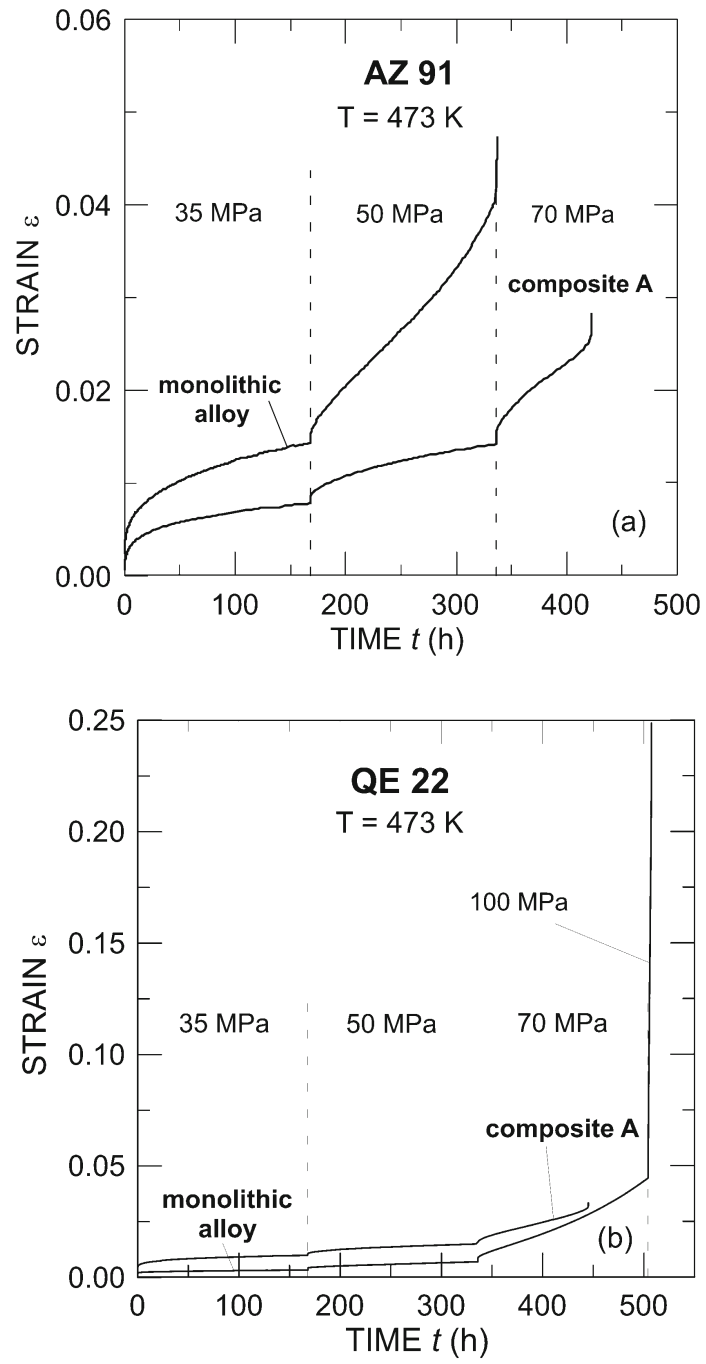

Fig. 8. Creep curves for (a) the AZ91 matrix alloy and its hybrid fibre-particle composite $\mathrm{A}$ and (b) the QE22 matrix alloy and its hybrid composite A. The preform for composite A consists of 8 vol.\% carbon short fibres and 16 vol.\% blocky-shaped SiC 600 particles - see Section 2. 
of the unreinforced AZ91 alloy and its composite are shown in Fig. 8a. Inspection of the creep data in Fig. 8a leads to the following observations. The composite exhibits a better creep resistance than the unreinforced AZ91 alloy over the stress levels used. By contrast, no beneficial effect of the hybrid reinforcement on the creep rate and thus no marked improvement of the creep resistance was found for the QE22-based composite (Fig. 8b). Metallographic investigation revealed a substantial difference between the microstructures of the two composites. Whereas no intensive precipitation was found in the $\mathrm{SiC} / \mathrm{AZ91}$ matrix interface (Fig. 9), Nd-rich phases were frequently formed at the $\mathrm{SiC} / \mathrm{QE} 22$ matrix interfaces during creep. Further, needle-shaped precipitates containing $\mathrm{Mg}$, Si and Nd were often observed in close proximity to the $\mathrm{MgO} / \mathrm{QE} 22$ matrix interfaces (Fig. 10). Fractographic investigation of the creep-fractured specimens revealed another difference between the creep fracture surfaces of the two composites. Whereas debonding in the AZ91 composite occurs between the reaction $\mathrm{MgO}$ zone at the carbon fibre surface and the matrix, it appears that debonding in the QE22 composite is the result of a separation along the matrix alloy and carbon fibre/reaction zone interface [11]. The strong bonding between carbon fibre surfaces and $\mathrm{MgO}$ reaction zones and $\mathrm{SiC} /$ matrix interfaces implies a very important role of the load transfer in creep strengthening of magnesium hybrid composites. This result confirms the previous conclusion for the particle-reinforced QE22 + SiC composite prepared by the powder metallurgy method and indicates the paramount importance of the choice of the composite matrix alloy and the reinforcement used.

\section{Concluding remarks}

The creep resistance of discontinuously reinforced magnesium composites can be significantly improved by comparison with the unreinforced matrix alloys in two separate ways. Direct strengthening of the composites arises mainly from effective load transfer, provided that no or non-significant debonding of the particle/matrix or fibre/matrix interfaces occurs. Indirect strengthening can arise from changes to the matrix microstructure in the composite by the addition of the reinforcement. An example of positive indirect strengthening is the presence of a threshold stress in the composite. Further, indirect composite strengthening may be caused by additional temperature-dependent precipitation processes that lead to an attractive interaction between dislocations and inherent second-phase particles. By contrast, matrix depletion due to preferential precipitation at the reinforcement/matrix interface can produce precipitate inhomogeneity and deficiency in the matrix pre-
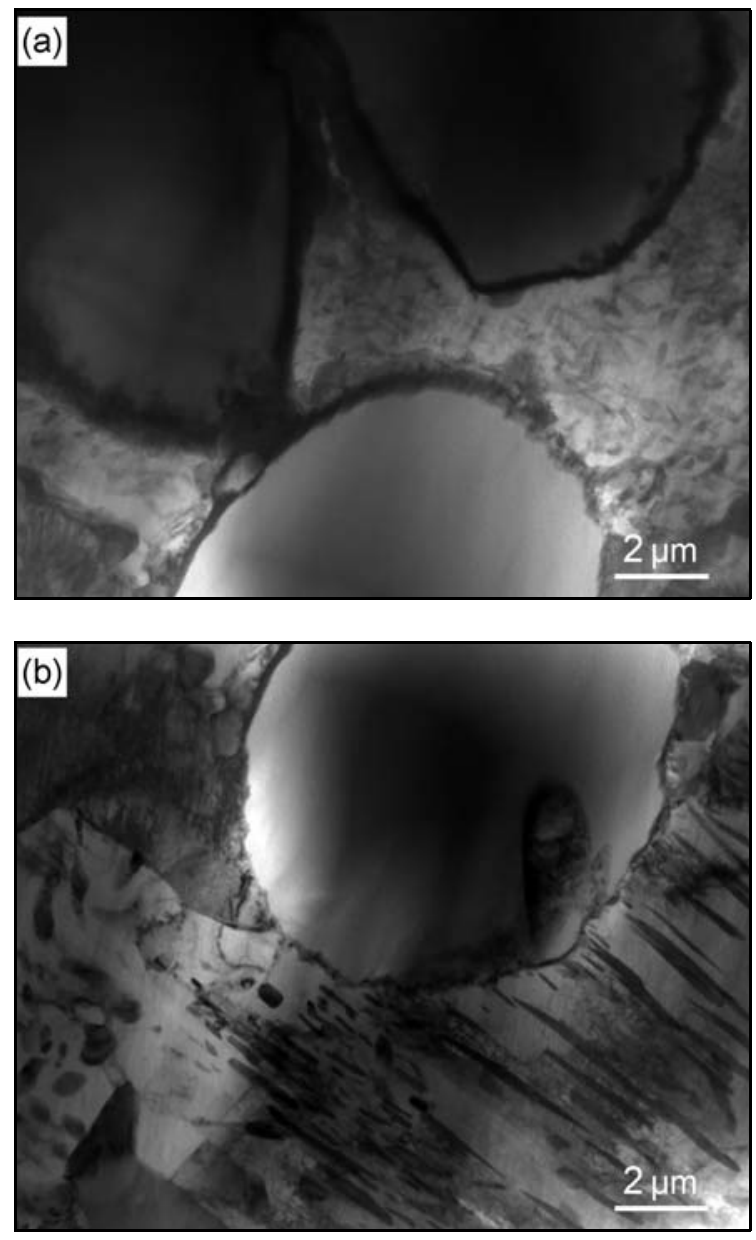

Fig. 9. TEM micrographs of the hybrid composite AZ91 showing (a) carbon fibre and $\mathrm{SiC}$ particles with $\mathrm{MgO}$ envelope and $\mathrm{Mg}_{17} \mathrm{Al}_{12}$ precipitates at their surfaces and (b) carbon fibre and $\mathrm{Mg}_{17} \mathrm{Al}_{12}$ precipitates at the fibre surface and in the matrix.

cipitate structure, leading to the composite weakening, which indicates the dominant importance of the choice of the matrix alloy and the reinforcement(s) in the composite design. It should be stressed that damage processes occurring at the interfaces between the reinforcement and the matrix and arising from reactions during composite processing and creep loading have to be included in an overall predictive model of the composite creep behaviour. However, the characteristics of these processes make a relevant analytical treatment of damage for any model of creep in metal matrix composites very difficult.

\section{Conclusions}

A comparison is made between the creep behaviour and characteristics of two magnesium unreinforced AZ91 and QE22 alloys and their discontinuously reinforced composites. Both of the squeeze-cast 

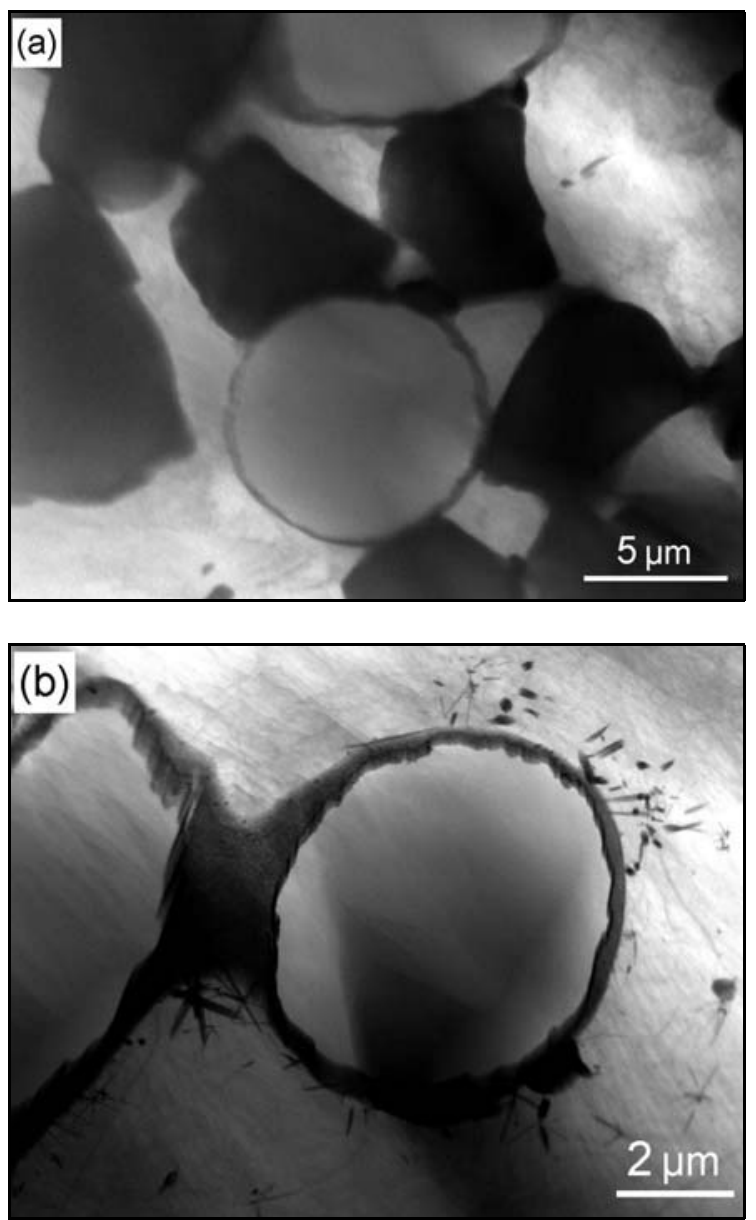

Fig. 10. TEM micrographs of the hybrid composite QE22 showing (a) carbon fibres and $\mathrm{SiC}$ particles and (b) needle-shaped precipitates containing $\mathrm{Mg}, \mathrm{Si}$ and $\mathrm{Nd}$ in the vicinity of the $\mathrm{MgO} /$ matrix interface.

short-fibre reinforced AZ91 and QE 22 composites exhibit improved creep resistance compared with their monolithic matrix alloys due to an effective load transfer in which part of the external load within the matrix is transferred to the reinforcement. Indirect composite strengthening may be caused by microstructural effects, leading to the existence of a threshold stress that increases the creep resistance. However, the indirect reinforcement effect can also produce weakening, as was documented in the case of the particlereinforced and hybrid QE22 composite. This suggests that direct composite strengthening by the load effect dominates over the indirect effect.

\section{Acknowledgements}

This paper is dedicated to Professor Pavel Lukáč on the occasion of his 80th birthday. The authors would like to express their gratitude to him for many stimulating and helpful discussions.
The work was realized at CEITEC - Central European Institute of Technology, with research infrastructure supported by the project CZ.1.05/1.1.00/02.0068 financed by European Regional Development Fund.

\section{References}

[1] Lewandowski, J. J.: In: Metal Matrix Composites. Ed.: Clyne, T. W. Oxford, Elsevier Science Ltd. 2000. doi:10.1016/B0-08-042993-9/00008-5

[2] Mordike, B. L., Kainer, K. U., Moll, F., Sommer, B.: In: Proceedings MAGNESIUM 97. Eds.: Aghion, E., Elizer, D. Beer-Sheva, Israel, Magnesium Research Institute (MRI) Ltd. 1998, p. 178.

[3] Sklenička, V., Svoboda, M., Pahutová, M., Kuchařová, K., Langdon, T. G.: Mater. Sci. Eng. A, 319-321, 2001, p. 741. doi:10.1016/S0921-5093(01)01023-1

[4] Svoboda, M., Pahutová, M., Kuchařová, K., Sklenička, V.: Mater. Sci. Eng. A, 324, 2002, p. 151. doi:10.1016/S0921-5093(01)01298-9

[5] Sklenička, V., Pahutová, M., Kuchařová, K., Svoboda, M., Langdon, T. G.: Metall. Mater. Trans, 33A, 2002, p. 883. doi:10.1007/1-4020-2112-7_21

[6] Sklenička, V., Langdon, T. G.: J. Mater. Sci., 39, 2004, p. 1647. doi:10.1023/B:JMSC.0000016164.40257.a9

[7] Pahutová, M., Sklenička, V., Kuchařová, K., Svoboda, M., Langdon, T. G.: Kovove Mater., 43, 2005, p. 34.

[8] Svoboda, M., Pahutová, M., Moll, F., Březina, J., Sklenička, V.: In: Proceedings Magnesium Alloys and their Applications. Ed.: Kainer, K. U. Weinheim, Wiley-CH 2000, p. 234.

[9] Pahutová, M., Sklenička, V., Kuchařová, K., Svoboda, M.: Int. J. Mater. Prod. Technol., 18, 2003, p. 116.

[10] Sklenička, V., Pahutová, M., Kuchařová, K., Svoboda, M., Kainer, K. U.: Mater. Sci. Forum, 419-422, 2003, p. 805 .

doi:10.4028/www.scientific.net/MSF.419-422.805

[11] Svoboda, M., Pahutová, M., Kuchařová, K., Sklenička, V., Kainer, K.: Mater. Sci. Eng. A, 462, 2007, p. 220. doi:10.1016/j.msea.2006.02.466

[12] Li, Y., Langdon, T. G.: Scripta Mater., 36, 1997, p. 1457. doi:10.1016/S1359-6462(97)00041-9

[13] Lagneborg, R., Bergman, B.: Metal Sci., 10, 1976, p. 20. doi:10.1179/030634576790431462

[14] Park, K. T., Lavernia, E. J., Mohamed, F. A.: Acta Metall. Mater., 42, 1994, p. 667. doi:10.1016/0956-7151(94)90264-X

[15] Nardone, V. C., Prewo, K. M.: Scripta Met., 20, 1986, p. 43. doi:10.1016/0036-9748(86)90210-3

[16] Mordike, B. L., Lukáč, P.: Surf. Interface Anal., 31, 2001, p. 682. doi:10.1002/sia1094

[17] Chmelík, F., Lukáč, P., Janeček, M., Moll, F., Mordike, B. L., Kainer, K. U.: Mater. Sci. Eng. A, 338, 2002, p. 1. doi:10.1016/S0921-5093(02)00086-2

[18] Mondal, A. K., Kumar, S.: Compos. Sci. Technol., 68, 2008, p. 3251. doi:10.1016/i.compscitech.2008.08.007

[19] Mondal, A. K., Kumar, S.: Compos. Sci. Technol., 69, 2009, p. 1592. doi:10.1016/i.compscitech.2009.02.038

[20] Moll, F., Chmelík, F., Lukáč, P., Mordike, B. L., Kainer, K. U., Langdon T. G.: Mater. Sci. Eng. A, 291, 2000, p. 246. doi:10.1016/S0921-5093(02)00086-2

[21] Sklenička, V.: Mater. Sci. Eng. A, 234-236, 1997, p. 30. doi:10.1016/S0921-5093(97)00172-X 
[22] Arunachaleswaran, A., Pereira, I. M., Dieringa, H., Huang, Y., Hort, N., Dwindaw, B. K., Kainer, K. U.: Mater. Sci. Eng. A, 460-461, 2007, p. 268. doi:10.1016/j.msea.2007.01.043
[23] Kumar, H., Chaudhari, G. P.: Mater. Sci. Eng. A, 607, 2014, p. 435. doi:10.1016/j.msea.2014.04.020 